\title{
Proposing a New Conceptual Model Predicting Consumer Videogame Engagement Triggered Through Playful-Consumption Experiences
}

\author{
Amir Zaib Abbasi ${ }^{1}$, Ding Hooi Ting, and Helmut Hlavacs ${ }^{2}$ \\ 'Department of Management and Humanities, Universiti Teknologi PETRONAS, \\ Tronoh, Malaysia \\ amir zaib abbasi@yahoo.co.uk \\ ${ }^{2}$ Research Group Entertainment Computing, University of Vienna
}

\begin{abstract}
The aim of the study is to propose a conceptual model which predicts consumer videogame engagement triggered by the playful-consumption experience of videogame-play. The proposed conceptual model is based on a review of past literature on experience and engagement in videogame studies. Moreover, this study employs the hedonic theory of consumption experience and the concept of consumer engagement in order to conceptualize and operationalize the construct of playful-consumption experience and consumer videogame engagement and accordingly, develops the conceptual model. Based on the conceptual model, this study has drawn related hypothesis. This study is unique in its investigation as it examines the idea of experience from the perspective of hedonic theory of consumption experience and whereas, engagement is studied from the previous work on consumer engagement. Besides, this conceptual model is new in the field of videogame literature that examines consumer videogame engagement and playful consumption experience concurrently and this model also predicts consumer videogame engagement that is provoked by the playful-consumption experience of videogame play.
\end{abstract}

Keywords: Experience, hedonic consumption experience, playful consumption experience, imaginal experience, emotional experience, sensory experience, engagement, consumer engagement, consumer videogame engagment, cognitive, affective and behaviroal engagement.

\section{Introduction}

The prevalence of playing videogames such as computer, mobile, portable and console videogames, has been raised significantly in the past decade [1]. Due to the popularity of videogame playing, the total consumers' spending on games industry has increased to $\$ 22.41$ billion [2]. This prominent growth in the videogame industry has 
encouraged academicians to research on videogame related issues. One of the key issues in videogame literature that has much debated is exploring and measuring the consumer's experiences, which arise from the interaction of a player, playing a videogame [3].

In similar vein, numerous academicians have investigated the concept of experience in videogame studies; some of the studies have qualitatively explored the term experience $[4,5]$ while, some studies have quantitatively measured the notion of experience $[6,7]$. The term experience has been studied through several theoretical constructs "absorption and flow, presence, immersion and engagement, gameflow, immersion and flow, presence, immersion, flow and absorption" by these studies [4, 5, 7-11] to measure the subjective-experience of videogame-play. Moreover, the study has related the notion of experience with immersion, which has been further explored in the application of new technologies. For instance, immersive virtual environments in digital humanities that further create a new human experiences by consuming the new media technology like interactive immersive environments with videogames [12].

In literature, there are other studies $[13,14]$ that have investigated the subjective experience of videogame-play but they termed as "game-engagement". Authors of these studies $[13,14]$ have used the following dimensions "presence, flow, immersion, absorption and involvement” to measure the subjective game-play experience.

Doing a critical analysis of the past studies, the present study has found that the main issue in the previous studies is, they have studied two different concepts (experience and engagement) with similar theoretical constructs for instance; authors of the study [7] have measured the subjective experience of videogame-play through these theoretical lenses (presence, flow, immersion and psychological absorption) and named as immersion. Whereas, authors of these studies [13, 14] have measured the term "engagement" in videogames as game-engagement and used the following theoretical dimensions flow, presence, absorption, involvement and immersion in order to quantify the subjective game-play experience. The same viewpoint has also been raised in the recent study [15] in which authors of the study have stated that prior studies have applied the concept of experience/immersion and engagement interchangeably to examine the subjective game-play experience as well as player's engagement in videogame playing. Another issue in the previous studies [7, 13, 14, 16] is, they have restricted the construct of experience and engagement to the use of only psychological dimensions presence, flow, immersion and psychological absorption. Besides, these studies have ignored the importance of studying behavioral elements in both of the constructs.

The main purpose of the study is twofold; first, this study considers engagement and experience as a separate concept whereby, experience recognizes as consumer's consumption experience that occurs from the consumption of the product which influences a consumer to further engage in the product $[17,18]$. These studies have also cleared the understanding between experience and engagement that consumption experience comes before the engagement in the product. This viewpoint is consistent with the following study [19] who has discussed in his study that consuming experience of ambient media leads consumers to further engage in the ambient media. 
Moreover, this study follows the viewpoint of [20] who added that engagement arises from the experiences that come from the interactions of the main stimuli (product or service) and therefore, this study attempts to propose a new conceptual model that predicts consumer videogame engagement triggered by the playful-consumption experience of videogame play. Another objective of the study is to expand the conceptual model through conceptualizing and operationalizing the construct of playful-consumption experience and consumer video-game engagement.

\section{Literature review}

Experience in videogame studies is a multifaceted construct, which has been explored and studied by several studies [4-7]. Among these studies, research done by [4] was first study in the videogame literature, who explored the experiences of videogame-players and defined such experiences as game immersion. In Addition, authors have further categorized the definitional construct of game immersion into three sub levels of experiences such as "engagement, engrossment, and total immersion". Another study by [5] who investigated the concept of immersion to understand the basic essentials of videogame-play experience. The study resulted in three factors "sensory-immersion, challenge-based immersion and imaginative-immersion" affecting the construct of immersion.

Literature review reports that these studies $[6,7,10,21,22]$ have examined the experiences of videogame-play for instance; the following studies [10, 21, 22] have considered the idea of experience as a multidimensional construct that comprises these dimensions "imaginative and sensory-immersion, competence, challenge, annoyance/tension, flow, positive and negative affect". Based on these dimensions, authors have developed and labeled a scale as game experience questionnaire (GEQ) for measuring the experiences of videogame play. But, the questionnaire lacks empirical validation [23]. In contrast to game experience questionnaire, these studies [4-7] have employed the theory of immersion to develop the instruments such as "immersion questionnaire [7] and game immersion questionnaire [6]" for describing the experiences of videogame-play. Moreover, immersion questionnaire has been developed through the efforts of [7] in which authors have applied such theoretical constructs "flow, presence, cognitive absorption and immersion" to develop a scale for measuring the experience of immersion in videogame-playing. While, another study [6] has employed the definition of immersion [4] to develop a scale for "game immersion experience" which is intended to measure the experiences of videogame-play. According to the study [4], immersion is defined as "three sub-levels of experiences" such as "engagement, engrossment and total immersion".

Recently, the research done by [15] has debated that few studies have employed the notion of experience/immersion and engagement in a similar manner to examine the experiences of videogame-play. This can be supported by these studies [13, 14] who have applied the term engagement to quantify the subjective experience of videogame-play. Another interesting point that has been raised is, authors of these 
studies [13, 14] have applied similar dimensions "flow, presence, absorption and immersion" to measure the construct game engagement, which have already been employed in the following study [7] to measure the experiences of videogame-play.

A critical evaluation of past researches that have utilized the notion of experience/immersion and engagement in videogame studies, the current study has found the following issues for instance; first, the concept of experience/immersion and engagement have been used interchangeably to measure the subjective experience of videogame play [7, 13, 14]. Second, authors have applied similar theoretical dimensions "flow, presence, absorption and immersion" to measure the experiences as well as player's engagement in videogame-play. Besides, authors have applied only psychological dimensions in the construct of game engagement and experience/immersion.

To address the above stated issues, the next section aims to propose a unique conceptual model that studies the concept of experience and engagement as two separate theoretical constructs. In this conceptual model, the present study employs the concept of experience from the context of hedonic theory given by [24] and whereas, engagement from the work of following studies [25-27].

\section{The Development of Conceptual Model and Study Propositions}

The notion of experience was initially presented by [24] in the field of consumption and marketing. Now onwards, the studying of experience has turned into a significant component to realize consumer's behavior [28]. Formerly, the researchers of marketing and consumer field, have applied the idea of consumption in only purchasing decisions. But, this viewpoint of the consumption, has been extended by the study [24] who has introduced the experiential features of the consumption. Moreover, a study [29] has contributed that a researcher can investigate the idea of consumption in terms of buying, usage and disposal. In similar vein, the following studies [30-32] have also added that consumption experience occurs in numerous ways for instance; when consumers are looking for a product, when consumers purchase the product or acquire any service and lastly, when consumers make use of the product or service. Among these consumption experiences, the present study is mainly interested in investigating the consumption experience that comes from the use of the product. Applying the concept of consumption experience in context of videogame-play, the consumption experience is assumed to achieve through the playful-consumption of a videogame product because a study has added that "playing a videogame is truly as experiencing a videogame" [33]. Moreover, researchers [34, 35] have considered the act of playing a videogame or consuming videogames as "playful-consumption experience". This is due to the reason that playful-consumption experience affiliates to intrinsically motivated consumer behavior that is usually done for its own benefit. Such consumption experience of videogame-play, further facilitates the videogame-consumers to experience a variety of hedonic elements relating to videogame-play such as imagination, emotional responses and multisensory attributes $[35,36]$. Furthermore, these hedonic elements 
"imagination, emotional responses and multisensory attributes" come under the umbrella of hedonic consumption. Authors of these studies [24, 37], have defined hedonic consumption as "those facets of consumer behavior that relate to consumers' emotive-responses, imaginary and multi-sensory aspects in using products". Besides, according to [24], videogame is one of the hedonic product because, the consumption of a videogame product as "playful-consumption" involves consumers" emotive-responses, imaginary and multi-sensory aspects.

In the following studies, researchers have further operationalized and categorized the hedonic consumption experience into three main experiences, explicitly, imaginal, emotional and sensory experiences [24, 38]. Imaginal experience states about mental events of visualizing things that are not considered as real and such visualizing is internal, personal and unspoken [39]. Hedonic consumption is connected with imaginal experience as a product has the potential to help consumers imagine actions that they want [24]. While, emotional experience denotes to emotive states that consumers experience with respect to particular activities. The following research [24] has added a product has the ability to arouse consumers' emotional state and therefore, emotional experience is linked with hedonic consumption. The last experience that is tied to hedonic consumption is sensory experience. Whereas, the study [24] has defined sensory experience as "the receipt of experience in multiple sensory modalities comprising sense of touch, sight, and sound".

In earlier debate, the study has defined and operationalized the term experience as "playful-consumption" from the perspective of hedonic consumption theory given by [24]. However, the term engagement is less defined in the above studies and therefore, the next debate will shed light on the concept of engagement in videogame.

The current article studies the concept of engagement in videogame literature as "consumer videogame engagement". This study takes a theoretical support from the following studies $[18,25,26]$ in order to define and conceptualize the concept of consumer videogame engagement. According to the authors, "engagement is a multi-dimensional construct which is subject to a context-specific expression of relevant cognitive, emotional and behavioral dimensions". Moreover, the study by [18] has further promoted that the process of engagement exhibits due to having two-way communications among the engagement-subject like "consumer/customer" and a specific engagement-object like a product, service or a brand, which finally helps in generating consumer engagement levels in terms of consumers' cognitive, affective and behavioral engagement. As a result of these definitions given by [18, 25, 26], this study defines consumer videogame engagement as "A psychological state that triggers due to two-way interactions between the consumer and videogame product, which generates different level of consumer engagement states (cognitive, affective and behavioral)". According to the definition of consumer videogame engagement, the construct of consumer videogame engagement is further conceptualized as three main states of engagement comprising cognitive, affective and behavioral engagement.

In spite of the fact, consumers gain playful-consumption experience through the consumption of a videogame product as "playing a videogame". Such playful-consumption experience refers to the notion of hedonic consumption experience, which relates to consumers' imaginal, emotional and sensory experience in 
the videogame-play. A study [40] has further added that this kind of experiences (playful-consumption experiences) are so interactive and co-creative that consumers get engaged cognitively, affectively and behaviorally in playing more videogames. On this basis, the present study proposes a unique conceptual model as shown in Figure: 1 that predicts consumer videogame engagement in terms of consumers' or video-gamers' cognitive, affective and behavioral engagement triggered by consumers' or video-gamers' playful-consumption experience in terms of their imaginal, emotional and sensory experience.

\subsection{Conceptual Model}

The following proposed conceptual model explains that when consumers play a videogame, they actually get an experience of playing which is termed as playful-consumption experience. Playful-consumption experience is further categorized as imaginal experience, emotional experience and sensory experience. This is consumers' playful-consumption experience that further motivates consumers to engage into videogame playing. This engagement is coined as consumer videogame engagement in the proposed conceptual model. The consumer videogame engagement is further classified into cognitive engagement, affective engagement and behavioral engagement.

Playful-Consumption Experience
Consumer Videogame

Engagement

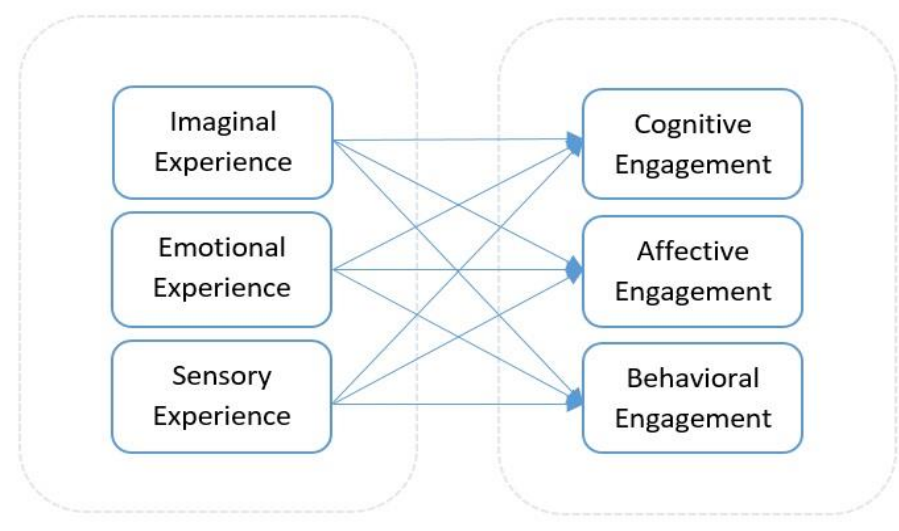

Figure: 1 Predicting Consumer Videogame Engagement Triggered by Playful-Consumption Experience

\subsection{Study hypothesis}

According to the proposed conceptual as shown in the Figure: 1, this study develops the following hypothesis.

Imaginal experience has a positive significant impact on cognitive engagement. 
Imaginal experience has a positive significant impact on affective engagement. Imaginal experience has a positive significant impact on behavioral engagement. Emotional experience has a positive significant impact on cognitive engagement. Emotional experience has a positive significant impact on affective engagement. Emotional experience has a positive significant impact on behavioral engagement. Sensory experience has a positive significant impact on cognitive engagement. Sensory experience has a positive significant impact on affective engagement. Sensory experience has a positive significant impact on behavioral engagement.

\section{Conclusions}

This study took an initiative to consider the concept of engagement and experience in videogame studies as a distinct construct and these constructs cannot be employed interchangeably to understand and examine the experiences of videogame-play as well as players' engagement in videogame playing. This perspective can be well understood from the work of [30-32] who defined that experience exits when customers consume the product or service and whereas, the state of engagement comes from such experiences that consumers have had with the consumption of a product [20]. Applying these concepts in the videogame context, experience is recognized as consumers' playful-consumption experience that gains when consumers consume the videogame product as "playing" a videogame on any platform. When consumers find such playful-consumption experiences as co-creative and interactive, then such experiences further provide consumers a kind of interface, whereby consumers become engaged in the videogame-play [40]. Therefore, this study has proposed a unique conceptual model that predicts consumer videogame engagement triggered by the playful-consumption experience of videogame-play.

\section{Contribution and Future Research}

This study contributes to videogame literature in several ways for instance; this study is first to employ the hedonic theory of consumption experience in the field of videogame studies, to examine the playful-consumption experience, namely, imaginal, emotional and sensory experience in videogame-play. Secondly, this study differentiates between the concept of experience and engagement in videogame studies because, previous researches [7, 13, 14] have applied the concept of experience and engagement interchangeably to examine the player's experiences and engagement in videogame play. This study further contributes to the past studies that experience comes first then such experiences further influence consumers to get engaged in the videogame-play. Moreover, this study employs the definition of consumer engagement that has been mentioned in the following studies $[18,25,26]$ to conceptualize consumer videogame engagement in videogame literature. The new perspective of engagement as "consumer videogame engagement", brings new insights in the previous studies [13, 
14] that have studied the notion of engagement in their studies. Thirdly, all previous work in the field of videogame literature, especially on measuring experiences $[6,7,10$, $21]$ as well as engagement $[13,14]$, are scarce to simultaneously examine the notion of experience and engagement within a model, which the current study addresses in the proposed model that predicts consumer videogame engagement triggered by playful-consumption experience of videogame play. This study is conceptual in nature and therefore, future study is warrant to validate the proposed model and the study propositions. Moreover, future work is in progress to develop a scale on playful-consumption experience and consumer videogame engagement.

\section{References}

1. Takatalo, J., et al., User Experience in Digital Games Differences Between Laboratory and Home. Simulation \& Gaming, 2011. 42(5): p. 656-673.

2. Association, E.S., Essential Facts about the Computer and Video Game Industry. Entertainment software association, 2015: p. 20.

3. Seo, Y., M. Buchanan-Oliver, and K.S. Fam, Advancing research on computer game consumption: A future research agenda. Journal of Consumer Behaviour, 2015. 14(6): p. 353-356.

4. Brown, E. and P. Cairns. A grounded investigation of game immersion. in CHI'04 extended abstracts on Human factors in computing systems. 2004. p. 1297-1300. ACM.

5. Ermi, L. and F. Mäyrä, Fundamental components of the gameplay experience: Analysing immersion. Worlds in play: International perspectives on digital games research, 2005. 37: p. 2.

6. Cheng, M.T., H.C. She, and L.A. Annetta, Game immersion experience: its hierarchical structure and impact on game-based science learning. Journal of Computer Assisted Learning, 2015. 31(3): p. 232-253.

7. Jennett, C., et al., Measuring and defining the experience of immersion in games. International journal of human-computer studies, 2008. 66(9): p. 641-661.

8. Costello, B. and E. Edmonds. A tool for characterizing the experience of play. in Proceedings of the Sixth Australasian Conference on Interactive Entertainment. 2009. p. 2. ACM.

9. Funk, J.B., T. Pasold, and J. Baumgardner. How children experience playing video games. in Proceedings of the second international conference on Entertainment computing. 2003. p. 1-14. Carnegie Mellon University.

10. IJsselsteijn, W., et al. Characterising and measuring user experiences in digital games. in International conference on advances in computer entertainment technology. 2007. 2(p. 27).

11. Sweetser, P. and P. Wyeth, GameFlow: a model for evaluating player enjoyment in games. Computers in Entertainment (CIE), 2005. 3(3): p. 3-3.

12. Lugmayr, A. and M. Teras. Immersive Interactive Technologies in Digital Humanities: A Review and Basic Concepts. in Proceedings of the 3rd International Workshop on Immersive Media Experiences. 2015. p. 31-36. ACM.

13. Brockmyer, J.H., et al., The development of the Game Engagement Questionnaire: A measure of engagement in video game-playing. Journal of Experimental Social Psychology, 2009. 45(4): p. 624-634.

14. Procci, K.C., The Subjective Gameplay Experience: An Examination of the Revised Game Engagement Model (PhD Diss). 2015, University of Central Florida Orlando, Florida.

15. Hookham, G., K. Nesbitt, and F. Kay-Lambkin. Comparing usability and engagement between a serious game and a traditional online program. in Proceedings of the Australasian Computer Science Week Multiconference. 2016. p. 54. ACM. 
16. Nordin, A.I., A. Denisova, and P. Cairns. Too Many Questionnaires: Measuring Player Experience Whilst Playing Digital Games. in Seventh York Doctoral Symposium on Computer Science \& Electronics. 2014. 69.

17. Bowden, J.L.-H., The process of customer engagement: A conceptual framework. Journal of Marketing Theory and Practice, 2009. 17(1): p. 63-74.

18. Hollebeek, L.D., Demystifying customer brand engagement: Exploring the loyalty nexus. Journal of Marketing Management, 2011. 27(7-8): p. 785-807.

19. Lugmayr, A., et al., Categorization of ambient media projects on their business models, innovativeness, and characteristics - evaluation of Nokia Ubimedia MindTrek Award Projects of 2010. Multimedia Tools and Applications, 2013. 66(1): p. 33-57.

20. Malthouse, E.C. and B.J. Calder, Comment: Engagement and Experiences: Comment on Brodie, Hollenbeek, Juric, and Ilic (2011). Journal of Service Research, 2011. 14(3): p. 277-279.

21. IJsselsteijn, W., et al. Measuring the experience of digital game enjoyment. in Proceedings of Measuring Behavior. 2008. p. 88. Maastricht Netherlands.

22. Poels, K., Y. de Kort, and W. Ijsselsteijn, FUGA-The fun of gaming: Measuring the human experience of media enjoyment. Deliverable D3. 3: Game Experience Questionnaire. FUGA project, 2008.

23. Norman, K.L., Geq (game engagement/experience questionnaire): a review of two papers. Interacting with Computers, 2013. 25(4): p. 278-283.

24. Hirschman, E.C. and M.B. Holbrook, Hedonic consumption: emerging concepts, methods and propositions. The Journal of Marketing, 1982: p. 92-101.

25. Brodie, R.J., et al., Customer engagement: conceptual domain, fundamental propositions, and implications for research. Journal of Service Research, 2011. 14(3): p. 252-271.

26. Brodie, R.J., et al., Consumer engagement in a virtual brand community: An exploratory analysis. Journal of Business Research, 2013. 66(1): p. 105-114.

27. Hollebeek, L., Exploring customer brand engagement: definition and themes. Journal of strategic Marketing, 2011. 19(7): p. 555-573.

28. Addis, M. and M.B. Holbrook, On the conceptual link between mass customisation and experiential consumption: an explosion of subjectivity. Journal of consumer behaviour, 2001. 1(1): p. 50-66.

29. Holbrook, M.B., Consumer research: Introspective essays on the study of consumption. 1995: Sage Publications.

30. Holbrook, M.B., The millennial consumer in the texts of our times: Experience and entertainment. Journal of Macromarketing, 2000. 20(2): p. 178-192.

31. Brakus, J. and B. Schmitt, S. Zhang (2008), "Experiental Attributes and Consumer Judgments, ”. Schmitt, BH; D. Rogers (eds), 2008.

32. Arnould, E., L. Price, and G. Zinkhan, Consumers-International edition. 2002, Boston, MA: McGraw Hill.

33. Salem, K. and E. Zimmerman, Rules of play. 2004, Mit Press.

34. Buchanan-Oliver, M. and Y. Seo, Play as co-created narrative in computer game consumption: The hero's journey in Warcraft III. Journal of Consumer Behaviour, 2012. 11(6): p. 423-431.

35. Holbrook, M.B., et al., Play as a consumption experience: The roles of emotions, performance, and personality in the enjoyment of games. Journal of Consumer Research, 1984. 11(2): p. 728-739.

36. Abbasi, A.Z., D.H. Ting, and A.B.S.A. Jamek. An integrated conceptual model for predicting behavioral learning triggered by video-game engagement: A mediating role of observational learning. in Game Physics and Mechanics International Conference (GAMEPEC), 2015. 2015. p. 11-15. IEEE.

37. Alba, J.W. and E.F. Williams, Pleasure principles: A review of research on hedonic consumption. Journal of Consumer Psychology, 2013. 23(1): p. 2-18. 
38. Wang, C.-L., et al., The influence of hedonic values on consumer behaviors: an empirical investigation in China. Journal of Global Marketing, 2000. 14(1-2): p. 169-186.

39. MacInnis, D.J. and L.L. Price, The role of imagery in information processing: Review and extensions. Journal of consumer research, 1987. 13(4): p. 473-491.

40. Caru, A. and B. Cova, A critical approach to experiential consumption: fighting against the disappearance of the contemplative time. Critical Marketing, 2003. 23: p. 1-16. 